show that the safe working resistance per square inch for mild-steel columns may reasonably be taken as twice as great as for cast-iron.

He concludes his strong argument in favor of the exclusion of the cast-iron columns from building construction, and the substitution therefor of steel columns, with the following recapitulation :

"The series of tests of cast-iron columns (herein referred to) largely destroys confidence in the cast-iron column designs of the past. The results of the tests constitute a revelation of a not very assuring character in reference to cast-iron columns now standing, and which may be loaded approximately up to specification amounts. They further show that, if cast-iron columns are designed with anything like a reasonable and real margin of safety, the amount of metal required dissipates any supposed economy over columns of mild steel. As a matter of fact, these results conclusively affirm what civil engineers have long known, that the use of cast-iron columns cannot be justified on any reasonable ground whatever."

W.

\title{
Franklin Institute.
}

[Proceedings of the stated meeting held Wednesday, September 21, 1898.]

HaLI OF THE FRanki, IN INSTITUTE, Philadel,Phia, September 21, i 898.

Mr. John Birkinbine, President, in the chair.

Present, 92 members and visitors.

Additions to membership since last report, 4.

Mr. Robert D. Kinney was elected a member of the Committee on Science and the Arts, for the unexpired term of Mr. P. A. Winand, resigned.

Mr. Paul J. Schlicht, of New York, presented a paper on "A New Process of Combustion." Mr. Schlicht's process is an automatic down-draught system, adapted to furnaces of all kinds ; not only to furnaces of steam boilers, but also to house heaters. The communication was discussed by Messrs. Outerbridge, Scott, LeVan and the author. The paper is reserved for publication, and the subject was referred for investigation and report to the Committee on Science and the Arts.

Mr. R. J. Fisher, of New York, exhibited and described the Fisher BookTypewriter. The machine is designed for printing directly in record books, and may be readily converted into an ordinary writing machine for correspondence. (Referred to the Committee on Science and the Arts.)

Mr. Ernest M. White, of Philadelphia, exhibited and described certain improvements in chimneys and globes for incandescent gas lights. They are designed, respectively, to permit the use of torn and otherwise imperfect 
mantles of the Welsbach type, which would otherwise have to be discarded, and to protect the light from extinguishment by wind or drafts.

The Secretary exhibited and described the Mason Safety-Tread for stairways, sidewalk lights, etc. An abstract of the monthly report appears in the fournal.

Adjourned.

WM. H. WAHL, Secretary.

\section{COMMITTEE ON SCIENCE AND THE ARTS.}

[Abstract of proceedings of the stated meeting held Wednesday, September 7 , 1898.1

Mr. Samuel Sartain, in the chair.

Reports on the following subjects were considered:

(No. 2003.) Automatic Air-Brake Mechanism.-G. F. Jeffries, Reading, $\mathrm{Pa}$.

(No. 2009.) Chimney for Incandescent Gas Lights.-Ernest M. White, Philadelphia. [Referred back to Sub-committee for revision.]

The following cases were terminated.

(No. 1977.) Trolley-Car Fender.-Henry Lotzgesell, Philadelphia.

ABsTRACr. - The device is made of three metal frames, of about the width of the car tracks, with rope netting stretched across them, and being hinged together and so mounted and secured to the front of the car that normally two of the frames form an inclined plane reaching from about the height of the car floor to a point very near the ground. The third frame stands upright at the back of the other two and near the car dasher.

The whole structure may be adjusted at any desired angle by chains and side bars, and the front edge of the lower frame is furnished with a buffer of soft material for the protection of a person struck by it.

The hinged sections are so connected that they will fold up partially when a heavy body falls upon them, thus furnishing a crib within which the person is held.

Provision is also made by which the whole structure can be folded up close to the car dasher, and for transferring the fender from one end of the car to the other. The device can be cheaply built from materials purchasable on the market.

The report speaks of the device as " a good one," but finds that almost all of the details thereof have been anticipated by other patentees. A list of these anticipating patents is appended to the report.

The invention is covered by letters-patent of United States, No. 570,099, October 27, I896, to Henry Lobzgesell. [Sub-Committee.-H. R. Heyl, Chairman; T. Carpenter Smith.] 